\title{
PERAN REGULASI DIRI DALAM BELAJAR DAN KETERLIBATAN AKADEMIK TERHADAP INTENSI MENGUNDURKAN DIRI DENGAN RESILIENSI SEBAGAI MEDIATOR
}

\author{
Pricilia Claudia Pattynama1, Riana Sahrani ${ }^{2}$, Pamela Hendra Heng ${ }^{3}$ \\ ${ }^{1}$ Program Studi Psikologi Jenjang Magister, Universitas Tarumanagara, Jakarta \\ Email: sisipriciliaclaudia@gmail.com \\ ${ }^{2}$ Fakultas Psikologi, Universitas Tarumanagara, Jakarta \\ Email: rianas@fpsi.untar.ac.id \\ ${ }^{3}$ Fakultas Psikologi, Universitas Tarumanagara, Jakarta \\ Email:pamelah@fpsi.untar.ac.id
}

\begin{abstract}
ABSTRAK
Pengunduran diri dari perkuliahan merupakan salah satu fenomena yang banyak terjadi pada mahasiswa, terutama mahasiswa strata 1 (S1) di institusi swasta. Penyebab utama fenomena ini adalah adanya intensi mengundurkan diri. Penelitian ini bertujuan untuk mengetahui peran regulasi diri dalam belajar dan keterlibatan akademik terhadap intensi mengundurkan diri dari perkuliahan. Secara khusus, penelitian ini bertujuan untuk menguji resiliensi sebagai variabel mediator. Penelitian ini menggunakan pendekatan kuantitatif, dengan 348 mahasiswa yang terdaftar di sebuah Universitas di Jakarta, Indonesia sebagai partisipan penelitian. Partisipan penelitian berusia 18 hingga 25 tahun. Pengambilan data dilakukan menggunakan empat alat ukur yang diadaptasi dari instrumen sebelumnya. Alat ukur tersebut mengukur regulasi diri dalam belajar, keterlibatan akademik, resiliensi dan intensi mengundurkan diri. Hasil penelitian menunjukkan bahwa resiliensi merupakan variabel mediator antara regulasi diri dalam belajar dan keterlibatan akademik terhadap intensi mengundurkan diri dari perkuliahan. Intensi tinggi untuk mengundurkan diri ditemukan pada mahasiswa di fakultas kedokteran serta mahasiswa tahun kedua. Hasil penelitian juga menunjukan bahwa keterlibatan akademik paling berkontribusi terhadap intensi mengundurkan diri dibandingkan regulasi diri dalam belajar dan resiliensi. Berdasarkan hasil penelitian, mahasiswa perlu meregulasi diri dalam perkuliahan, membangun rasa terlibat dengan proses studi, serta perlu memiliki resiliensi agar semakin memiliki intensi rendah untuk mengundurkan diri.
\end{abstract}

Kata Kunci: mahasiswa, regulasi diri dalam belajar, keterlibatan akademik,intensi mengundurkan diri, resiliensi.

\begin{abstract}
Drop out of college students is a rising phenomenon, especially in private institution. The main cause of this phenomenon is drop out intention. The goal of this research was to investigate the role of self-regulated learning and academic engagement to predict college student drop out intention. Specifically, this research aim to test resilience as a mediator variable between self-regulated learning and academic engagement in drop out intention. This study conducted quantitative approach with 348 student enrolled in a University in Jakarta, Indonesia as participant. Participants' age range from 18 to 25 years. Data collected from four instruments adapted from previous instrument measured self regulated learning, academic engagement, resilience and drop out intention. Result showed that resilience mediated self regulated learning and academic engagement to drop out intention. High level of drop out intention found in medical student and second year student. Academic engagement has the most contribution to drop out intention. Result showed that college student need to develop self-regulated learning, feel engage with their learning process in institution, and have resilience in order to reduce drop out intention.
\end{abstract}

Keywords: college students, self regulated learning, academic engagement, drop out intention, resilience. 


\section{PENDAHULUAN}

\section{Latar Belakang}

Pengunduran diri dari institusi pendidikan merupakan salah satu fenomena yang terjadi di hampir seluruh perguruan tinggi di Indonesia (Kementrian Riset, Teknologi, dan Pendidikan Tinggi Republik Indonesia, 2017). Pengunduran atau yang juga dikenal dengan istilah drop out, merupakan sebuah kondisi ketika mahasiswa baik memilih untuk tidak melanjutkan pendidikan formal sebelum memperoleh gelar akademis baik secara sukarela maupun keputusan dari institusi pendidikan (Tudela, 2014; Kim \& Kim, 2018). Di Indonesia, institusi swasta memiliki persentase mahasiswa mengundurkan diri sebesar $4 \%$ dan institusi negeri memiliki persentase sebesar 0,3\% (Kementrian Riset, Teknologi, dan Pendidikan Tinggi Republik Indonesia, 2017). Data tersebut menunjukan bahwa institusi swasta lebih banyak memiliki mahasiswa yang mengundurkan diri dibandingkan institusi negeri. Lebih jauh lagi, ditemukan bahwa pengunduran diri lebih sering terjadi pada mahasiswa di strata 1 dibandingkan strata 2 (Aarreniemi-Jokipelto \& Bäck, 2014). Fenomena ini juga ditemukan pada sebuah Universitas swasta di Jakarta. Data dari Biro Akademik di Universitas tersebut menunjukan bahwa sebanyak 87 mahasiswa mengundurkan diri pada semester ganjil 2017/2018, 71 mahasiswa mengundurkan diri pada semester genap 2017/2018, dan 68 mahasiswa mengundurkan diri pada semester hingga ganjil 2018/2019. Dari data tersebut ditemukan bahwa ada lima program studi tertinggi dalam hal jumlah mahasiswa mengundurkan diri, yaitu program studi kedokteran, ekonomi manajemen, ekonomi akuntansi, teknik sipil dan teknik arsitektur.

Hal utama yang mendorong mundurnya mahasiswa dari perkuliahan yaitu adanya intensi tinggi untuk mundur kuliah (Eicher, Staerkle dan Clemence, 2014). Intensi mengundurkan diri yaitu keinginan atau rencana mahasiswa untuk keluar dari institusi pendidikan. Kejadian ini tidak terjadi serta merta, tetapi melalui proses panjang. Hal ini terjadi karena siswa hilang motivasi belajar (Balkis, 2017), merasa tidak terlibat (engage) dalam proses akademik (Truta, Parv, \& Topala, 2018), tidak berkomitmen terhadap institusi pendidikan, serta dipengaruhi oleh kondisi dukungan sosial (Braxton, Vesper, \& Hosslet, 1995; Otis, Grouzet, \& Palletier, 2005; Braxton, et al, 1995; Hausmann, Schofield \& Woods, 2007; Zea, Reisen, Bell, \& Caplan, 1997; Haussmann et al, 2007, Thomas, 2000; dalam Eicher, Staerkle, \& Clemence, 2014). Secara eksternal, beberapa penyebab intensi mengundurkan diri terdiri dari peraturan institusi pendidikan dan status sosial ekonomi (Eicher, Staerkle, \& Clemence, 2014). Peraturan pendidikan di wilayah setempat juga berkontribusi dalam ketentuan terjadinya fenomena drop out. Peraturan Pemerintah Riset, Teknologi, dan Pendidikan Tinggi 44 Pasal 16 tentang Standar Nasional Pendidikan Tinggi menyatakan bahwa masa studi minimal mahasiswa strata 1 (S1) adalah 3,5 - 4 tahun dan maksimal 7 tahun (Kementerian Riset, Teknologi, dan Pendidikan Tinggi Direktorat Jenderal Pembelajaran dan Kemahasiswaan, 2016). Oleh karena itu, mahasiswa yang belum menyelesaikan studi sebelum waktu maksimal, akan dikeluarkan dari institusi pendidikan. Hal tersebut memungkinkan adanya pengeluaran dari pihak institusi, atau pengunduran diri secara sukarela setelah memperkirakan bahwa dirinya tidak mampu menyelesaikan studi sesuai batas waktu yang ditentukan.

Pada umumnya, para peserta didik yang berada di jenjang S1 berada pada kategori usia dewasa awal yaitu 19 hingga 23 tahun (Kementrian riset, teknologi dan pendidikan tinggi, dalam Yud, 2018). Pada kategori usia tersebut, mahasiswa akan mengalami berbagai tantangan dalam hal pendidikan, emosi, dan finansial (Corathers, Kichler, Fino, et al, dalam Anasuri \& Anthony, 2018). Individu di kategori usia ini mengalami kesulitan dalam menghadapi beragam tantangan karena ada keterbatasan pengetahuan serta kesiapan dalam menangani situasi tersebut. Banyak perubahan besar di kehidupan mahasiswa pada waktu yang bersamaan dengan situasi pendidikan 
yang baru, misalnya meninggalnya orangtua, orang terdekat atau adanya tanggung jawab lainnya seperti bekerja. Dalam kondisi ini, mahasiswa membutuhkan keterampilan untuk bertahan dalam proses akademik meskipun mengalami berbagai tantangan. Sebuah variabel psikologis yang dapat menjelaskan ketahanan individu meskipun berada dalam situasi sulit yaitu resiliensi (Anasuri \& Anthony, 2018).

Resiliensi adalah sebuah kemampuan personal yang memampukan individu bertahan dalam berbagai tantangan yang dihadapi (Connor \& Davidson, dalam Fletcher \& Sarkar, 2013). Resiliensi merupakan sebuah variabel positif dan terbukti berhubungan positif dengan berbagai variabel dalam konteks pendidikan, di antaranya adalah pencapaian akademik (De la Fuente, Fernández-Cabezas, Cambil, et al, 2017), kepuasan hidup (Stack-Cutler, Parrila, \& Torppa , 2015), dan resiliensi juga terbukti berhubungan negatif dengan kelelahan akademik atau academic burn out (Ríos-Risquez, García-Izquierdo, Sabuco-Tebar, et al, 2016). Dalam proses belajar, siswa akan menghadapi beragam situasi menantang. Meskipun demikian, siswa yang resilien terbukti mampu mengerahkan diri dan menggunakan segala yang ada pada dirinya dalam pengerjaan tugas, mampu mencari bantuan ketika dibutuhkan, dapat membangun dan mempertahankan hubungan positif dengan guru dan teman, serta mampu merencanakan, membuat pilihan, dan menjalankan pilihan yang sudah diambil. Siswa yang resilien juga memiliki orang-orang yang diandalkan ketika mengalami kesulitan dalam proses belajar. Kemampuan ini akhirnya membuat siswa memiliki intensi mengundurkan diri yang lebih rendah (Lessard, Fortin, Bulter-Kisber, et al, 2014). Penelitian lainnya menemukan bahwa siswa yang mengundurkan diri adalah siswa yang tidak resilien (Finn \& Rock, dalam Norris, 2014). Resiliensi juga terbukti dapat diprediksi oleh regulasi diri dalam belajar (Artuch-Garde, Gonzalez-Torres, de la Fuente, et al, 2017). Regulasi diri dalam belajar adalah kemampuan untuk mengarahkan diri sendiri yang mencakup aktivitas pemantauan proses kognitif oleh diri sendiri. Sama seperti resiliensi, regulasi diri dalam belajar terbukti dapat memprediksi hasil positif dalam konteks akademik, yaitu pencapaian akademik, motivasi akademik, self-efficacy, dan juga goal setting (McInerney \& King, dalam Schunk \& Greene, 2018). Intervensi terhadap kemampuan regulasi diri dalam belajar juga terbukti dapat menurunkan variabel psikologi yang bersifat negatif seperti prokrastinasi (Kirana, Sahrani, \& Hastuti, 2016). Selain itu, ditemukan pula bahwa dimensi efikasi diri yang merupakan dimensi regulasi diri dalam belajar, berhubungan dan mampu memprediksi resiliensi (Cassidy, 2015). Sebaliknya, ditemukan hasil yang menunjukkan bahwa tidak ada hubungan antara regulasi diri dalam belajar dengan resiliensi (Schutte, 2012). Regulasi diri dalam belajar mencakup dimensi perencanaan, self-monitoring, evaluasi diri, refleksi, usaha dan efikasi diri. Sebagian besar penelitian terdahulu telah melakukan penelitian mengenai dimensi motivasi dan efikasi diri terhadap intensi mengundurkan diri (Fan \& Wolters, 2014). Jika siswa memiliki efikasi diri yang rendah dalam mata pelajaran, maka ia lebih berisiko untuk mengundurkan diri dari proses studi.

Selain regulasi diri dalam belajar, resiliensi dan intensi mengundurkan diri juga dapat diprediksi oleh keterlibatan mahasiswa dalam proses akademik (student engagement). Variabel ini juga terbukti membawa hasil positif dalam proses pendidikan. Keterlibatan siswa dalam proses akademik adalah usaha psikologis siswa terhadap pembelajaran, pemahaman, dan penguasaan berbagai keterampilan dan pengetahuan pada berbagai tugas di sekolah (Newmann, Wehlage, \& Lamborn, dalam Alrashidi, Phan, \& Ngu, 2016). Siswa yang memiliki pengalaman positif dan lebih terlibat dengan aktivitas di sekolah memiliki level resiliensi yang tinggi (Giavana \& Lafreniere, 2014). Harper (dalam Truta, Parv, \& Topala, 2018) menunjukkan bahwa drop out akan semakin mungkin terjadi jika siswa tidak merasa terlibat dengan proses akademik. Keterlibatan siswa dapat dilihat dari beberapa indikator, seperti kehadiran, partisipasi di aktivitas 
kemahasiswaan, serta ketaatan terhadap peraturan sekolah. Siswa yang jarang hadir di kelas, tidak mengikuti aktivitas kemahasiswaan, serta melakukan pelanggaran di sekolah cenderung memiliki intensi untuk mengundurkan diri (Rumberger \& Lim, 2008; Alexander, et al, 2001; Rumberger \& Rotermund, 2012; dalam Christenson, Reschly, \& Wylie, 2012). Siswa yang memiliki keterlibatan dalam proses akademik dengan menunjukkan antusiasme, rasa bangga, dan terinspirasi oleh sekolah memiliki intensi mengundurkan diri yang rendah (Truta, Parv, \& Topala, 2018). Berbagai penelitian tersebut menunjukkan bahwa baik resiliensi maupun intensi mengundurkan diri dapat diprediksi oleh keterlibatan siswa.

Dengan adanya kemampuan untuk memprediksi keberhasilan akademik di berbagai penelitian sebelumnya, maka regulasi diri dalam belajar, keterlibatan akademik dan resiliensi diduga dapat memprediksi intensi mengundurkan diri. Diduga ketiga variabel tersebut berhubungan negatif dengan intensi mengundurkan diri. Regulasi diri dalam belajar perlu diteliti kembali karena belum ditemukan peran regulasi diri dalam belajar sebagai sebuah konstruk utuh terhadap intensi mengundurkan diri. Padahal regulasi diri dalam belajar terbukti dapat membawa hasil positif dalam proses pendidikan. Namun, belum terbukti apakah regulasi diri dalam belajar secara utuh mampu memprediksi intensi mengundurkan diri. Selain itu, masih sedikit penelitian yang melihat kemampuan ketiga variabel tersebut dalam memprediksi intensi mengundurkan diri. Hanya ditemukan sebuah artikel penelitian yang membahas mengenai keterlibatan akademik (Truta, Parv, dan Topala, 2018) dan resiliensi akademik (Lessard, 2014; Butler-Kisber, Fortin, et al, 2014) pada siswa yang sudah keluar dari proses studi.

Adanya fenomena mundur dari perkuliahan merupakan hal yang mengkhawatirkan dan perlu dicegah. Apabila terjadi terus-menerus, hal ini akan membawa dampak negatif baik kepada pihak institusi seperti terpengaruhnya hasil akreditasi institusi atau penilaian terhadap institusi. Beberapa standar penilaian akreditasi oleh Badan Akreditasi Nasional Perguruan Tinggi mencakup prestasi mahasiswa, waktu tempuh untuk menyelesaikan studi, serta hal lainnya yang berhubungan dengan mahasiswa dan alumni (BAN-PT, 2011). Sementara itu, dampak negatif bagi pihak mahasiswa yaitu kesulitan dalam memperoleh pekerjaan di kemudian hari serta kerugian biaya dari pihak mahasiswa atau keluarga mahasiswa karena membayar biaya perkuliahan.

Kemampuan variabel-variabel tersebut dalam memprediksi intensi mengundurkan diri pada mahasiswa S1 perlu diketahui guna menghindari kerugian pada pihak institusi maupun mahasiswa. Dengan mengetahui hubungan antara variabel-variabel pada penelitian ini, diharapkan dapat dilakukan tindak lanjut untuk menurunkan intensi untuk mengundurkan diri dari proses studi. Rumusan masalah dalam penelitian ini adalah apakah regulasi diri dalam belajar dan keterlibatan siswa berperan terhadap intensi mengundurkan diri dengan resiliensi sebagai mediator.

\section{Rumusan Masalah}

Apakah regulasi diri dalam belajar dan keterlibatan siswa berperan terhadap intensi mengundurkan diri dengan resiliensi sebagai mediator?

\section{METODE PENELITIAN}

\section{Partisipan dan Prosedur Penelitian}

Penelitian ini dilakukan dengan desain kuantitatif non-eksperimental. Pemilihan sampel dilakukan secara convenience sampling. Teknik ini merupakan pengambilan sampel secara tidak 
acak. Peneliti memilih teknik ini dengan alasan kemudahan dalam memperoleh sampel. Teknik pengambilan sampel dalam penelitian ini dilakukan dengan cara memberikan kuesioner kepada mahasiswa S1 yang ditemui oleh peneliti. fokus meneliti sekelompok mahasiswa yang terdaftar di fakultas-fakultas yang mengalami fenomena pengunduran diri tinggi, yaitu Fakultas Kedokteran, Ekonomi Manajemen, Ekonomi Akuntansi, Teknik Sipil dan Teknik Arsitektur. Partisipan harus terdaftar aktif sebagai mahasiswa di Universitas X. Penelitian ini dilakukan kepada mahasiswa di seluruh semester dengan rentang usia 18 hingga 25 tahun.

Peneliti menghubungi pihak administrasi Universitas $\mathrm{X}$ untuk mengetahui data fakultas dengan persentase dropout tertinggi. Data yang diharapkan adalah fakultas dengan angka drop out tertinggi pada 1 (satu) tahun terakhir. Ditemukan bahwa ada 5 program studi dengan angka mahasiswa pengunduran diri tertinggi, yaitu Fakultas Kedokteran, Fakultas Ekonomi Program Studi Akuntansi, Fakultas Ekonomi Program Studi Manajemen, Fakultas Teknik Program Studi Teknik Arsitektur, dan Fakultas Teknik Program Studi Teknik Sipil. Sambil menunggu persetujuan perizinan penelitian, peneliti melakukan pencarian alat ukur untuk mengukur variabel penelitian. Peneliti menghubungi pembuat alat ukur melalui e-mail dan berhasil memperoleh izin dari seluruh pembuat alat ukur. Peneliti kemudian melakukan adaptasi terhadap alat-alat ukur dengan mentranslasi alat ukur ke dalam bahasa Indonesia. Kemudian, hasil translasi tersebut dinilai oleh para ahli bahasa. Butir translasi kemudian di adaptasi agar sesuai dengan konteks partisipan. Butir adaptasi dinilai oleh para ahli di bidang psikologi dalam hal kalimat, konteks, serta kesesuaian butir-butir soal yang sudah di translasi dalam mengukur dimensi.

Peneliti kemudian melakukan pilot study untuk menguji alat-alat ukur tersebut kepada 43 (empat puluh tiga) mahasiswa S1. Hasil pilot study kemudian di analisis menggunakan SPSS Versi 16 untuk mengetahui validitas dan reliabilitas alat ukur. Setelah alat ukur siap, maka dilakukan pengambilan data dengan cara masuk ke kelas partisipan, atau menyebarkan kuseioner di luar kelas kepada mahasiswa yang ditemui oleh peneliti. Peneliti juga menyebaran kuesioner online bagi partisipan yang keberatan mengisi kuesioner fisik. Peneliti memperoleh data sebanyak 374 data. Namun, ditemukan 26 partisipan yang mengisi dengan jawaban yang serupa dari awal hingga akhir kuesioner. Dengan demikian, jumlah data yang diperoleh dan dapat digunakan sebanyak 348 data.

\section{Pengukuran}

Pada penelitian ini, digunakan 4 (empat) alat ukur yang diadaptasi dari College Persistence Quesionnaire (Davidson, Beck, \& Milligan, 2009), Self Regulated Learning Self Report Scale (Pitkethyl \& Lau, 2015), Student Course Engagement Scale (Lin \& Huang, 2018), serta Four Subscales of Adult Personal Resilience (Taormina, 2015). Instrumen adaptasi alat ukur tersebut di uji coba kepada 43 (empat puluh tiga) mahasiswa S1 di Universitas X. Peneliti melakukan uji validitas dan reliabilitas untuk seluruh alat ukur. Uji validitas berupa validitas konten dan face validity dilakukan kepada seluruh alat ukur. Validitas konten dilakukan dengan berkonsultasi kepada 3 (tiga) ahli yang memahami konstruk alat ukur. Proses ini dilakukan sebelum melakukan face validity. Face validity dengan menanyakan pendapat para partisipan uji coba terkait pemahaman terhadap kalimat butir-butir soal. Hasil uji face validity kepada 43 (empat puluh tiga) partisipan menunjukkan bahwa seluruh kalimat pertanyaan pada seluruh alat ukur dapat dipahami oleh partisipan. Selain itu dilakukan pula analisis butir soal dengan menggunakan Corrected Item Total Correlation. Analisis ini dilakukan untuk mengetahui apakah sebuah butir soal selaras dengan butir-butir soal lainnya dalam mengukur dimensi tertentu. Nilai Corrected Item Total Correlation harus r >.20 (Bowling, 2014; Viswanathan, 
2005). Jika ada nilai $\mathrm{r}<.20$ maka butir tersebut tidak bersama-sama mengukur dimensi yang sama dengan butir soal lainnya. Seluruh alat ukur memiliki nilai $r>.20$, kecuali alat ukur intensi mengundurkan diri memiliki 2 butir soal yang tidak valid sehingga tidak dilibatkan dalam analisis data. Uji reliabilitas alat ukur dilakukan dengan membandingkan koefisien Alpha Cronbach pada setiap dimensi alat ukur dengan standar minimal yang diterima yaitu $\alpha>.50$.

Tabel 1

Alat Ukur Penelitian

Variabel

Regulasi Diri dalam Belajar

\section{Nama Alat Ukur}

Self Regulated Learning Self Report Scale (Pitkethyl \& Lau, 2015). $\alpha=.627$ hingga $\alpha=.855$

\section{Dimensi}

\section{1. planning}

2. self monitoring

3. evaluation

4. reflection

5. effort

6. self efficacy

\section{Contoh Butir Soal}

Saya menentukan cara mengatasi masalah sebelum bertindak.

Saya mengecek hasil kerja saya sebelum dikumpulkan

Saya menganggap belajar di Kampus adalah hal penting.

2. Attitude engal engagement

3. Skill engagement

4. Performance engagement

5. Interactional engagement

$\alpha=.616$ hingga $\alpha=.788$

1. Determination

2. Endurance

3. Adaptability

4. Recuperability
Saya mampu bertahan dalam masa-masa sulit.
Personal Resilience

(Taormina, 2015)

$\alpha=.816$ hingga $\alpha=.875$

\section{College Persistence}

Mengundurkan Diri
Quesionnaire (Davidson,

Beck, \& Milligan, 2009)

$\alpha=.646$ hingga $\alpha=.730$,

dimensi institutional

commitment $(\alpha=.445)$

\section{Academic integration}

2. Social integration

3. Supportive Service

Satisfaction

4. Degree commitment

5. Institutional commitment

6. Academic

conscientiousness
Pada saat ini, seberapa yakin anda akan memperoleh gelar sarjana?

\section{HASIL DAN PEMBAHASAN}

Uji hipotesis dilakukan menggunakan teknik Process oleh Hayes (2013) yang merupakan pembaharuan dari teknik causal step oleh Baron dan Kenny (1986) dan Sobel test (1982, dalam Hayes, 2009). Tanpa melibatkan resiliensi sebagai mediator, regulasi diri dalam belajar dan keterlibatan akademik secara bersamaan berperan signifikan terhadap intensi mengundurkan diri. Nilai $F=76.918$ dan $\operatorname{sig}(p)=0.000<0.01, R^{2}=0.555$ atau berkontribusi sebesar 55,5\% terhadap intensi mengundurkan diri. Berdasarkan regresi berganda tanpa melibatkan mediator, nilai standardized coefficients regulasi diri dalam belajar yaitu $-0.096, \mathrm{t}=-1.681$ dan $\operatorname{sig}(\mathrm{p})=$ $0.094<0.05$. Hal ini menunjukan bahwa tanpa resiliensi sebagai mediator, regulasi diri dalam belajar tidak berperan signifikan terhadap intensi mengundurkan diri. Namun, dengan melibatkan mediator, regulasi diri dalam belajar berperan signifikan terhadap intensi mengundurkan diri dengan efek total (total effect) sebesar $-0.3615, \mathrm{p}=0.000<0.01, \mathrm{R}^{2}=$ 0.3991. Variabel regulasi diri dalam belajar berkontribusi sebesar 39,91\% terhadap intensi mengundurkan diri. Berdasarkan regresi berganda tanpa melibatkan mediator, nilai standardized coefficients keterlibatan akademik yaitu $-0.096, \mathrm{t}=-0.496$ dan sig $(\mathrm{p})=0.000<0.05$. Hal ini menunjukan bahwa keterlibatan akademik berperan signifikan terhadap intensi mengundurkan diri. Dengan adanya mediator, keterlibatan akademik juga berperan signifikan terhadap intensi 
mengundurkan diri dengan efek total sebesar $-0.4523, \mathrm{p}=0.000,<0.01, \mathrm{R}^{2}=0.3027$. Variabel keterlibatan akademik berkontribusi sebesar 30,27\% terhadap intensi mengundurkan diri. Peran resiliensi sebagai mediator dapat diketahui dengan melihat output Process pada bagian indirect effect. Melalui output Process, variabel dapat dikatakan menjadi mediator dengan mengacu kepada rentang batas keyakinan interval bawah atau LLCI dan batas keyakinan interval atas ULCI. Hasil analisis data dengan melibatkan mediator menunjukan bahwa resiliensi merupakan mediator antara regulasi diri dalam belajar dan keterlibatan akademik. Resiliensi menjadi mediator antara regulasi diri dalam belajar terhadap intensi mengundurkan diri sebesar -0.1318 . Batas keyakinan interval bawah atau LLCI $=-0.2473$ dan ULCI $=-0.0166$. Jika nol berada pada rentang LLCI hingga ULCI, maka resiliensi mampu menjadi mediator variabel independen terhadap variabel dependen. Resiliensi juga dapat memediasi keterlibatan akademik terhadap intensi mengundurkan diri. Efek tidak langsung (indirect effect) dari keterlibatan akademik terhadap intensi mengundurkan diri yaitu sebesar - 0.0590 dengan rentang LLCI $=-0.1120$ dan $\mathrm{ULCI}=-0.0073$. Hal ini menunjukan bahwa resiliensi dapat menjadi variabel mediator baik pada regulasi diri dalam belajar dan keterlibatan akademik. Dengan demikian maka hipotesis penelitian ini diterima. Hipotesis penelitian ini menyatakan bahwa regulasi diri dalam belajar dan keterlibatan akademik berperan terhadap intensi mengundurkan diri dengan resiliensi sebagai mediator. Hasil analisis data menunjukan bahwa resiliensi mampu menjadi mediator antara regulasi diri dalam belajar dan keterlibatan akademik terhadap intensi mengundurkan diri. Hasil pengujian tersebut menunjukan bahwa regulasi diri dalam belajar tidak berperan signifikan terhadap intensi mengundurkan diri, kecuali jika resiliensi dilibatkan sebagai mediator. Berdasarkan hasil tersebut dapat disimpulkan bahwa dengan meningkatkan regulasi diri dalam belajar, resiliensi pun akan meningkat, sehingga intensi mengundurkan diri akan menurun. Dengan demikian, dapat pula dikatakan bahwa meskipun mahasiswa memiliki regulasi diri dalam belajar yang baik, tetapi jika tidak memiliki ketahanan dalam menghadapi masalah di perkuliahan, maka mahasiswa tetap berpotensi memiliki intensi tinggi untuk mengundurkan diri.

Selain itu, ditemukan pula bahwa mahasiswa yang berintensi tinggi terbanyak berasal dari mahasiswa Fakultas Kedokteran. Hal ini mungkin disebabkan karena mahasiswa di Fakultas Kedokteran memiliki kurikulum yang padat serta beban belajar yang berat. Berdasarkan diskusi dengan mahasiswa Fakultas Kedokteran di Universitas X, Fakultas kedokteran tidak menggunakan sistem SKS seperti fakultas lain di Universitas tersebut. Selain beban kurikulum, level stress (Ludwig, Burton, Weingarten, et al, 2015) dan kelelahan akademik dapat memengaruhi intensi mengundurkan diri (Jackson, Shanafelt, Hasan, et al, 2016). Selain itu, dalam profesi kedokteran, dokter seringkali akan menghadapi situasi yang tidak pasti atau ambigu (ambiguity). Situasi ambigu terjadi ketika ditemukan banyak ketidakpastian dalam hal respon pasien, reaksi obat yang disarankan, serta kebenaran diagnosa terhadap pasien. Para dokter disarankan memiliki toleransi terhadap kemungkinan situasi yang tidak pasti tersebut (ambiguity tolerance) agar tidak menyebabkan stress, kecemasan, dan depresi (Afsar \& Kulsoom, 2015; Weissenstein, Ligges, Brouwer, et al, 2014).

Hasil penelitian juga menunjukan bahwa mahasiswa yang memiliki intensi tinggi untuk mengundurkan diri berasal dari mahasiswa semester 4 atau di tahun kedua. Hal ini merupakan temuan yang cukup baru, karena penelitian-penelitian terdahulu cenderung menemukan intensi mengundurkan diri pada mahasiswa tahun pertama. Hal ini mungkin terjadi karena mahasiswa tahun kedua mengalami hal yang disebut dengan sophomore slump (Furr \& Gannaway, 1982; Lemons \& Richmond, 1987, dalam Walsh, 2013). Sophomore slump ditandai dengan adanya kebingungan, kecemasan, dan ketidakpastian yang dirasakan pada tahun kedua di proses perkuliahan. Schaller (dalam Walsh, 2013) menjelaskan bahwa pada tahun pertama mahasiswa 
cenderung merasakan kebahagiaan yang berasal dari proses sosialisasi dengan lingkungan baru. Namun, pada tahun ini mahasiswa cenderung fokus pada kehidupan sosial sehingga kurang fokus terhadap pendidikannya. Pada tahun kedua, mahasiswa secara perlahan mulai merasakan tekanan besar dan rasa frustasi dari tanggung jawab sebagai seorang mahasiswa yang sebenarnya. Hal ini juga mulai muncul karena mulai ada keharusan bagi mahasiswa dalam memikirkan langkah studi berikutnya. Penemuan Schaller ini sesuai dengan penemuan pendahulunya yaitu Furr dan Gannaway (dalam Walsh, 2013). Mereka menyatakan bahwa mahasiswa tahun kedua memang lebih matang daripada mahasiswa tahun pertama. Namun, mereka belum sepenuhnya siap untuk menghadapi berbagai alternatif yang disajikan oleh institusi pendidikannya. Feldman dan Newcomb (dalam Walsh, 2013) juga menemukan bahwa mahasiswa tahun kedua kehilangan rasa puas terhadap perguruan tinggi. Mereka cenderung merasa seolah-olah kebahagiaan di tahun pertama telah hilang. Perasaan ini mungkin muncul karena mahasiswa tahun kedua sudah dituntut untuk mengambil berbagai keputusan terkait masa depannya (Richmond dan Lemons, dalam Walsh, 2013). Mereka pun menyarankan perlunya dilakukan mentoring dan konseling dari institusi pendidikan mahasiswa. Konsep sophomore slump tersebut menjelaskan penemuan di penelitian ini. Mahasiswa yang berintensi tinggi terbanyak berasal dari mahasiswa tahun kedua.

\section{KESIMPULAN DAN SARAN}

Analisis data menunjukan bahwa hipotesis penelitian di terima. Hasil penelitian menunjukan resiliensi merupakan mediator antara regulasi diri dalam belajar dan keterlibatan akademik terhadap intensi mengundurkan diri. Hasil penelitian ini juga menunjukan bahwa jika mahasiswa semakin mampu meregulasi diri dalam perkuliahan, maka mahasiswa semakin tidak memiliki intensi mengundurkan diri. Selain itu, semakin mahasiswa terlibat dengan dunia perkuliahannya, maka mahasiswa semakin tidak memiliki intensi mengundurkan diri dari perkuliahan. Selain itu, berdasarkan uji regresi sederhana ditemukan bahwa regulasi diri dalam belajar berperan sebesar $\mathrm{R}^{2}=.159$ atau sebesar $15.9 \%$ terhadap intensi mengundurkan diri. Sementara itu, keterlibatan akademik berperan sebesar $\mathrm{R}^{2}=.303$ atau sebesar $30.3 \%$ terhadap intensi mengundurkan diri. Secara bersamaan, regulasi diri dalam belajar dan keterlibatan akademik berperan sebesar $\mathrm{R}^{2}$ $=.308$ atau sebesar 30.8\% terhadap intensi mengundurkan diri. Sementara itu, resiliensi berperan sebesar $\mathrm{R}^{2}=.148$ atau sebesar $14.8 \%$ terhadap intensi mengundurkan diri. Hasil uji regresi tersebut menunjukan bahwa keterlibatan akademik memiliki kontribusi terbesar terhadap intensi mengundurkan diri.

Dengan adanya penelitian ini maka diketahui bahwa regulasi diri dalam belajar, keterlibatan akademik dan resiliensi sangat diperlukan dalam proses pendidikan agar mahasiswa tidak berintensi untuk mengundurkan diri dari pendidikan. Oleh karena itu, pihak Universitas dapat merancang program pelatihan regulasi diri dalam belajar serta pelatihan guna meningkatkan resiliensi mahasiswa terhadap masalah di perkuliahan. Selain itu, guna meningkatkan keterlibatan akademik, maka disarankan pihak Universitas mewajibkan mahasiswa untuk terlibat pada minimal 1 Unit Kegiatan Mahasiswa (UKM) agar mahasiswa semakin memiliki rasa memiliki terhadap institusi pendidikan serta membangun engagement di lingkungan perkuliahan. Selain itu, melalui penelitian ini juga diketahui bahwa keterlibatan akademik memiliki kontribusi terbesar pada intensi mengundurkan diri dibandingkan dengan regulasi diri dalam belajar dan resiliensi. Oleh karena itu, mahasiswa perlu membangun rasa terlibat dengan institusi pendidikan dengan cara mengikuti Unit Kegiatan Mahasiswa yang disediakan oleh pihak Universitas. Selain itu, mahasiswa juga perlu menyadari bahwa regulasi diri dalam belajar juga perlu ditingkatkan dengan membuat perencanaan yang jelas sebelum mengerjakan tugas, menentukan target yang 
memungkinkan untuk dicapai, serta perlu melakukan evaluasi terhadap keberhasilan rencana yang sudah dibuat. Dengan membiasakan proses ini, mahasiswa dapat menjadi pembelajar mandiri. Resiliensi perlu ditingkatkan dengan cara lebih percaya diri, melatih keterampilan pemecahan masalah, mandiri, serta dengan mengingat tujuan utama dan manfaat menjalani perkuliahan.

Salah satu kelemahan penelitian ini adalah menggunakan teknik pengambilan sampel secara convenience. Teknik pengambilan sampel dilakukan berdasarkan kemudahan peneliti untuk mencari partisipan penelitian. Sebaiknya penelitian berikutnya mengambil sampel secara purposive dengan kriteria mahasiswa yang sudah terbukti mengalami intensi mengundurkan diri yang tinggi. Selain itu, jumlah populasi penelitian ini tergolong besar sehingga diperlukan jumlah sampel yang juga besar agar dapat merepresentasikan populasi secara lebih akurat. Oleh karena itu, penelitian berikutnya perlu menggunakan jumlah sampel yang lebih besar. Hal ini dapat diterapkan baik pada saat pengambilan data maupun pada tahap uji coba alat ukur adaptasi. Jumlah sampel juga perlu diperbanyak saat uji coba alat ukur. Hal ini perlu dilakukan agar dapat melakukan analisis validitas konstruk dengan metode confirmatory factor analysis. Metode ini dinilai lebih akurat dalam menganalisis validitas konstruk karena mampu mengetahui kemampuan dimensi dalam mengukur konstruk. Penelitian berikutnya juga dapat melakukan penelitian yang bersifat jangka panjang atau longitudinal. Penelitian jangka panjang memungkinkan peneliti untuk memperoleh level intensi mengundurkan diri mahasiswa pada periode yang lebih panjang.

\section{Ucapan Terima Kasih (Acknowledgement)}

Terima kasih kepada pihak Biro Akademik Universitas X serta para Dekan atau Ketua Program Studi Kedokteran, Ekonomi Manajemen, Ekonomi Akuntansi, Teknik Sipil dan Teknik Arsitektur atas izin yang diberikan untuk melakukan penelitian.

\section{REFERENSI}

Afsar, N., \& Kulsoom, B. (2015).Stress, anxiety, and depression among medical students in a multiethnic setting. Neuropsychiatric Disease and Treatment, 1713.

Alrashidi, O., Phan, H.P., \& Ngu, B.H. (2016). Academic engagement: An overview of its definitions, dimensions, and major conceptualisations. International Education Studies, $9(12), 41-52$.

Anasuri, S., \& Anthony, K. (2018). Resilience levels among college students: A comparative study from two Southern states in the USA. Journal of Humanities and Social Science, 23(1), $52-73$.

Aarreniemi-Jokipelto, P., \& Bäck, A. (2014). Exploring Opportunities to Boost Adult Students' Graduation-The Reasons behind the Delays and Drop-Outs of Graduation. International Association for Development of the Information Society.

Artuch-Garde, R., Gonzales-Torres, Md.C.., de la Fuente, J, et al. (2017). Relationship between resilience and self-regulation: A study of Spanish youth at risk of social exclusion. Frontiers in Psychology, 8(612), 1 - 11.

Badan Akreditasi Nasional Perguruan Tinggi. (2011). Buku III Pedoman Penyusunan Borang. Diunduh pada 5 April 2018 dari https://banpt.or.id/instrumen/permen/Exhibit \%2021\%20Instrument\%20AIPT\%20BUKU\%203\%20BORANG\%20AIPT\%202011.pdf 
Balkis, M. (2017). Academic amotivation and intention to school dropout: the mediation role of academic achievement and absenteeism. Asia Pacific Journal of Education, 38(2), 257 270.

Baron, R.M \& Kenny, D.A. (1986). The moderator-mediator variable distinction in social psychological research: Conceptual, strategic, and statistical consideration Journal of Personality and Social Psychology, 51(6), $1173 \quad-1182$.

Bowling, A. (2014). Research Methods in Health: Investigating Health and Health Services $4^{\text {th }}$ edition. Berkshire: McGraw Hill

Cassidy, S. (2015). Resilience building in students: the role of academic self-efficacy. Frontiers in psychology, 6, 1781.

Christenson, S.L., Reschly, A.L., \& Wylie, C. (2012). Handbook of Research on Student Engagement. London: Springer Science Business Media.

Davidson, W. B., Beck, H. P., \& Milligan, M. (2009). The college persistence questionnaire: Development and validation of an instrument that predicts student attrition. Journal of College Student Development, 50(4), 373-390.

De la Fuente, J., Fernández-Cabezas, M., Cambil, M., Vera, M. M., González-Torres, M. C., \& Artuch-Garde, R. (2017). Linear relationship between resilience, learning approaches, and coping strategies to predict achievement in undergraduate students. Frontiers in psychology, 8, 1039.

Eicher, V., Staerkle, C., \& Clemence, A. (2014). I want to quit education: A longitudinal study of stress and optimism as predictors of school dropout intention. Journal of Adolescence, $37,1021-1030$.

Fan, W., \& Wolters, C.A. (2014). School motivation and high school dropout: The mediating role of educational expectation. British Journal of Educational Psychology, $84,22-39$.

Fletcher, D. \& Sarkar, M. (2013). Psychological resilience. European Psychologist, 18(1), 12 23.

Giavana, J., \& Lafreniere, K. (2014). Exploring the role of school engagement in predicting resilience among Bahamian youth. Journal of Black Psychology, 40(1), 47 - 68.

Hayes, A. F. (2013). Introduction to Mediation, Moderation, and Conditional Process Analysis. New York: Guilford Publications, Inc.

Kementerian Riset, Teknologi, dan Pendidikan Tinggi Direktorat Jenderal Pembelajaran dan Kemahasiswaan. (2016). Standar Nasional Pendidikan Tinggi (SN Dikti). Diunduh pada 5 April 2018 dari http://bpm.umsida.ac.id/wp-content/uploads/2017/08/3.-StandarNasional-Pendidikan-Tinggi-SN-Dikti.pdf

Kementerian Riset, Teknologi, dan Pendidikan Tinggi Republik Indonesia. (2017). Statistik Pendidikan Tinggi. Jakarta: Pusdatin Iptek Dikti, Setjen, kemenristekdikti.

Kirana, A., Sahrani, R., Hastuti, R. Intensi pelatihan self-regulated learning dalam mereduksi prokrastinasi akademik siswa. Provitae Jurnal Psikologi Pendidikan, 7(1), 20 - 36.

Kim, D., \& Kim, S. (2018). Sustainable education: analyzing the determinants of university student dropout by nonlinear panel data models. Sustainability, 10(4), 954.

Lin, S. H., \& Huang, Y. C. (2018). Assessing college student engagement: development and validation of the student course engagement scale. Journal of Psychoeducational Assessment, 36(7), 694-708. 
Lessard, A., Fortin, L., Butler-Kisber, L., et al. (2014). Analyzing the discourse of dropouts and resilient students. The Journal of Educational Research, $\quad$ 107(2), 103 110.

Norris, M.D. (2014). At risk students and resililency. Electronic Theses, Projects, and Dissertations. Diunduh dari http://scholarworks.lib.csusb.edu/etd pada 27 Februari 2019.

Pitkethly, A. J., \& Lau, P. W. (2016). Reliability and validity of the short Hong Kong Chinese Self-Regulation of Learning Self-Report Scale (SRL-SRS-C). International Journal of Sport and Exercise Psychology, 14(3), 210-226.

Ríos-Risquez, M. I., García-Izquierdo, M., Sabuco-Tebar, E. de los A., Carrillo-Garcia, C., \& Martinez-Roche, M. E. (2016). An exploratory study of the relationship between resilience, academic burnout and psychological health in nursing students. Contemporary Nurse, 52(4), 430-439.

Schunk, D.H \& Greene, J.A. (2018). Handbook of Self-Regulation of Learning and Performance. New York: Taylor \& Francis.

Schute, S. (2012). The Relationship between Resilience, Self-Regulation and the Academic Performance of Learners Living in Townships under Adverse Circumstances. (Disertasi Doktoral) diunduh dari https://www.semanticscholar.org/paper/The-relationshipbetween- resilience\%2C-and-the-of-inSchutte/358f0435060759a27bb5d7b23a6c41ceb6772c15

Stack-Cutler, H. L., Parrila, R. K., \& Torppa, M. (2014). Using a Multidimensional Measure of Resilience to Explain Life Satisfaction and Academic Achievement of Adults With Reading Difficulties. Journal of Learning Disabilities, 48(6), 646-657.

Taormina, R. J. (2015). Adult personal resilience: A new theory, new measure, and practical implications. Psychological Thought, 8(1), 35-46.

Truta, C., Parv, L., \& Topala, I. (2018). Academic engagement and intention to drop out: Levers for sustainability in higher education. Sustainability MDPI, 10(12), $1-11$.

Tudela, H.E.V. (2014). A theoritical approach to student drop out. Revista Digital de Investigacion en Docencia Universitaria, 8(1), 59 - 74.

Viswanathan, M. (2005). Measurement Error and Research Design. New Delhi: Sage Publications.

Walsh, M.E. (2013). The Retention Puzzle Reconsidered: Second Year Student Attitudes and Experiences with Advising. (Disertasi Doktoral). Diunduh dari https://core.ac.uk/download/pdf/37774384.pdf

Weissenstein, A., Ligges, S., Brouwer, B., Marschall, B., \& Friederichs, H. (2014). Measuring the ambiguity tolerance of medical students: a cross-sectional study from the first to sixth academic years. BMC Family Practice, 15(1)

Yud. 2018. Menristekdikti: Mahasiswa Indonesia Mencapai 7,5 Juta. Diunduh dari $\begin{array}{lllll}\text { www.beritasatu.com } & \text { pada } & 18 & \text { Februari } & 2019\end{array}$ https://www.beritasatu.com/nasional/521969-menristekdikti-mahasiswa indonesia mencapai-75-juta.html 